\title{
O MÉTODO DIALÓGICO DO TEATRO PARA O DESENVOLVIMENTO E A RECUPERAÇÃO DE DROGADOS
}

\author{
Márcia Pompeo Nogueira ${ }^{1}$
}

Este artigo apresenta uma paralelo entre o Método

Dialógico de Teatro para o Desenvolvimento e um processo de criação teatral com um grupo de drogados em recuperação, que aconteceu em Bournemouth, Inglaterra, baseado no pressuposto de que aqueles que passaram pelo problema das drogas poderiam dar uma idéia melhor, aos alunos secundaristas, sobre os riscos de consumir drogas.

Palavras-chave: criação teatral, escola, drogas.

Abstract

This paper presents a parallel between the Dialogical Theatre for Development method and a theatre devising process developed with a recovering drug addicts group, which took place in Bournemouth, England, based on the assumption that those who lived through the drug problem could give a better idea, to secondary school students, about the risks of drugs.

Keywords: devising theatre, drugs, school. 


\section{Introdução}

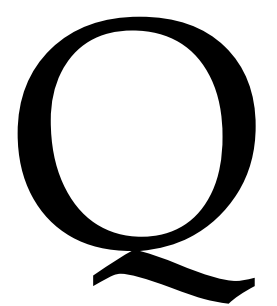

uando Sharon Muiruri abordou,emjaneirode1999, um grupo de drogados em recuperação, em Boscombe, Bournemouth, Inglaterra, ela queria criar uma peça para ampliar o debate sobre o problema das drogas nas escolas. Sua idéia era de que aqueles que passaram pelo problema das drogas poderiam dar uma idéia melhor, aos alunos secundaristas, sobre os riscos de consumir drogas. O grupo de Teatro Vita $N_{o v a}{ }^{2}$ foi formado e, apesar da maioria dos participantes nunca ter feito teatro, criou a peça Scratchin' the Surface, através de um processo muito profundo e rico artisticamente. Foi inicialmente apresentado no Centro Artístico Cultural de Bournemouth para uma plateia que incluía muitos drogados em recuperação. O espetáculo lotava todas as noites, muitos drogados em recuperação vinham assistir a peça, todas as noites. Este foi um resultado inesperado da peça: não era somente um meio para gerar, entre os jovens, uma consciência em relação ao problema das drogas, mas era também uma revelação e uma inspiração para aqueles em recuperação.

Seguindo esta resposta positiva do público, Vita Nova levou a peça para o Rehabilitation House (Centro de Reabilitação) para pessoas em fase inicial de recuperação. A experiência de tratamento em casas de reabilitação era parte do passado de todo o grupo Vita Nova. O retorno que tiveram lá foi extremamente positivo. O linguajar de rua usadona peça era omesmoda plateia, aempatia era total, muitos drogados em recuperação pediram para entrar no grupo de teatro.

As autoridades educacionais, entretanto, reagiram negativamente quanto à permissão do Vita Nova entrar nas escolas, por conta do histórico dos membros do grupo. Entretanto,

1 Professora do Departamento de Artes Cênicas, Centro de Artes, UDESC. Coordenadora do Núcleo de Formação de Facilitadores - FOFA - livros publicados: Teatro com Meninos e Meninas de Rua: nos caminhos do Ventoforte e Teatro na Comunidade: Interações, Dilemas e Possibilidades.

2 Do Latin, Vida Nova. a autenticidade do trabalho abriu muitas portas. Cartas de especialistas de programas de educação contra as drogas, depois de assistirem a peça, ajudaram o grupo a quebrar as resistências, recomendando o trabalho:

Eu (Colin Swan) trabalhei por 15 anos como voluntário e coordenador do serviço de aconselhamento no departamento de drogas do distrito de Bournemouth. Por um tempo (de fato por vários anos) eu dei palestras em escolas sobre o tema do abuso de drogas. Parei porque eu cheguei à conclusão de que eu não estava fazendo nada de bom e eu não tinha credibilidade. Esta é a melhor coisa que eu já vi para apoiar a esperança de que pode haver uma forma de influência e de prevenir os jovens de se tornarem usuários dependentes de drogas. Do meu ponto de vista, dizer "não" às drogas não é suficiente e nunca será. Esta peça vai funcionar (MUIRURI, 1999, anexo 4, p.32).

A solução encontrada foi apresentar a peça no Centro Artístico Cultural de Bournemouth para para estudantes secundaristas de teatro. Para os estudantes que assistiram a peça e participaram das discussões que sempre aconteciam após a peça, aquela era uma oportunidade única de conversar com pessoas que tinham "estado lá". Isso era algo impossível para os professores ou membros da polícia que faziam parte de campanhas de conscientização sobre drogas, como podemos ver a partir de um depoimento do aluno:

Parecia que não estávamos apenas ouvindo o que deveríamos fazer, de pessoas que nunca tinham tomado drogas. Era gente falando sobre o que eles realmente não conheciam. Alguns professores ficavam dizendo "você não deve usar drogas", quando eles nunca fizeram isso, de modo que eles não sabiam (In: Muiruri, 2000, p. 15).

Conversar com as pessoas [os atores] depois [da peça] foi realmente interessante porque tudo era dito verdadeiramente e podíamos fazer qualquer pergunta (MUIRURI, 1999, p.8). 
Após uma apresentação feita de noite, na Universidade de Bournemouth, em maio de 1999, a oficial de polícia Constable Mike Barlett e Jan Moody de Poole, da Assessoria de Aconselhamento e Serviços de Apoio ao Ensino, disse que eles queriam que a peça fosse vista por todas as crianças acima de 10 anos (MUIRURI, 2000, p. 1).

A peça finalmente saiu em turnê pelas escolas secundárias, em Bournemouth, Poole e quase todas as escolas em Dorset [Inglaterra]. Do outono de 1999 ao Verão de 2000 quase 7.000 pessoas assistiram a peça (MUIRURI, 2000, p. 2). Eles também se apresentaram no Presídio Guys March para uma unidade livre de drogas. A peça também foi apresentada, com sucesso, na conferência da National Drama, em York, no ano 2000, e no Congresso da IDEA Associação Internacional de Drama e Teatro na Educação - em Bergen, Noruega, em 2001.

Sharon e Vita Nova montaram uma nova peça chamada $A$ Mula, em Novembro de 2000, inspirada numa reportagem da Radio Four sobre o tráfico de drogas da Colômbia para Nova York e depois para a Europa. Esta nova peça representou um avanço importante para o grupo. Novos membros da comunidade de drogados em recuperação foram integrados ao grupo e eles puderam melhorar o seu trabalho teatral, bem como a sua reflexão sobre os problemas da droga além do universo dos usuários.

Sharon criou em seguida um novo projeto, motivado pela relação entre o Vita Nova e a polícia, durante as apresentações nas escolas. Desde o início a peça Scratchin' the Surface recebeu o apoio da polícia, que os acompanhava nas apresentações nas escolas ${ }^{3}$, e eles desenvolveram uma relação interessante e rara:

Em praticamente todas as apresentações que fizemos, a polícia estava presente. Eles nos ajudavam a montar e desmontar o cenário. Em certa ocasião, quando nos perdemos, alguém viu, da van que

$3 \mathrm{Na}$ Inglaterra este é um comportamento padrão. Trata-se do que eles chamam de polícia comunitária que acompanha a apresentação de grupos de teatro nas escolas. nos levava para as escolas, um carro da polícia e disse desconfiado (e numa linguagem um pouco mais colorida do que a citada aqui): - "O que será que um carro de polícia está fazendo nos seguindo?" Outro membro olhou para fora e respondeu: - "Fica tranquilo, é a nossa polícia!"

Quando completamos uma longa turnê, o policial da comunidade que esteve conosco durante todos aqueles meses fez um discurso comovente para nós. Ele falou sobre o privilégio que tinha sido estar conosco e que esperava que o grupo o considerassse como amigo (MUIRURI, 2000, p. 20).

Esta oportunidade única de reunir grupos que estão geralmente em lados opostos, representou um notável desenvolvimento que Sharon quis festejar e levar adiante através de uma nova produção teatral. Sua idéia foi montar Sonhos de uma Noite de Verão, de Shakespeare, integrando os dois grupos no elenco. Ambos aceitaram o convite e se dispuseram a trabalhar em conjunto.

\section{Scratchin' the Surface como um modelo de um Teatro Dialógica para o Desenvolvimento}

Depois de assistir ao lançamento de Scratchin' the Surface, no Centro Cultural de Bournemouth, em maio de 1999, fiquei fascinada pela qualidade artística do trabalho, mas fiquei especialmente impressionada com a discussão após a peça. A atmosfera era profunda. O público - muitos drogados em recuperação, alguns parentes dos atores e algumas autoridades educacionais - ficou tocado pela veracidade da interpretação dos conteúdos difíceis da peça. Sharon coordenou os debates após o espetáculo. Havia muito respeito. Ela não dominava o debate em nenhum momento, agia sempre de forma solidária, perguntando quem queria responder às perguntas. A confiança entre os membros do grupo Vita Nova e Sharon era evidente. Eu podia identificar imediatamente os aspectos de Teatro para o Desenvolvimento, que aprendi em outros 
projetos, ${ }^{4}$ onde os participantes e não o facilitador estavam no centro. Foi possível identificar a relação democrática entre eles. Desde aquele dia eu fiquei interessada em saber mais sobre os métodos de trabalho do grupo e sobre o processo criativo, para investigar as relações entre o trabalho do Vita Nova e o Método Dialógico de Teatro para o Desenvolvimento.

A principal característica do Teatro Dialógico para o Desenvolvimento ${ }^{5}$, que é uma metodologia de trabalho teatral de base freireana, é a transformação dos participantes de objetos em sujeitos dos projetos de desenvolvimento. Seria o trabalho de Sharon um exemplo deste tipo de teatro? Toda a bibliografia sobre o Teatro para o Desenvolvimento é referente a trabalhos realizados no chamado Terceiro Mundo, principalmente na África. Poderia um trabalho feito no continente europeu ser classificado como Teatro Dialógico para o Desenvolvimento?

Sharon não conhecia o Teatro Dialógico para o Desenvolvimento, mas mesmo assim pude identificar interessantes semelhanças entre seu trabalho e esta metodologia. Analisando o processo de criação de Scratchin' the Surface alguns paralelos se destacaram: Sharon agiu como uma facilitadora. Ela procurou os drogados em recuperação no espaço deles: o Clubhouse - um lugar de encontro e base de informação para pessoas em recuperação - porque sabia que "eles estariam muito nervosos se viessem para um espaço que não conheciam, encontrar uma desconhecida" (MUIRURI, 1999, p. 5). Lá, ela se aproximou de um grupo que já estava envolvido com teatro, um grupo que estava ensaiando uma peça escrita por eles, sobre o tratamento de recuperação.

4 Meu primeiro contato com o Teatro para o Desenvolvimento foi em 1998, quando interagi com um professor visitante do Reino Unido, Dan Baron Cohen, com quem desenvolvi o projeto Desenterrando o Futuro. Em 1999, durante meu doutorado na Inglaterra pude aprofundar meu entendimento sobre esta abordagem teatral.

5 Sobre o Teatro Dialógico para o Desenvolvimento ver NOGUEIRA, Marcia Pompeo. Towards a Poetically Correct Theatre for Development. Tese de Doutorado defendida na Exeter University, Inglaterra, em 2002.
Sharon propôs a criação de uma peça sobre drogas para levar para as escolas. Ela não trouxe um roteiro pré estabelecido do que fazer ou uma peça pronta, sua proposta era criar uma peça e levá-la para as escolas. Eles imediatamente gostaram da ideia. Para aqueles que entraram no terrível mundo do vício fazia sentido ajudar as crianças a não seguirem os seus passos. Entendiam que seria uma oportunidade abordar as pessoas da idade que tinham quando começaram a usar drogas. Eles tinham algo para contribuir para os jovens, de forma que pudessem ter uma escolha informada.

Quando eu estava na escola, veio um policial. Eu já estava usando drogas. Eu sabia mais sobre isso do que ele. Esta é realmente uma boa idéia, "injetar"... talvez não seja a palavra ... Se alguma coisa deste tipo entrasse na escola, com pessoas que tivessem passado pela experiência, isto iria fazê-los pensar. Sim ... eu acho que é uma boa idéia. Eu estou nessa (MUIRURI, 1999, p. 5).

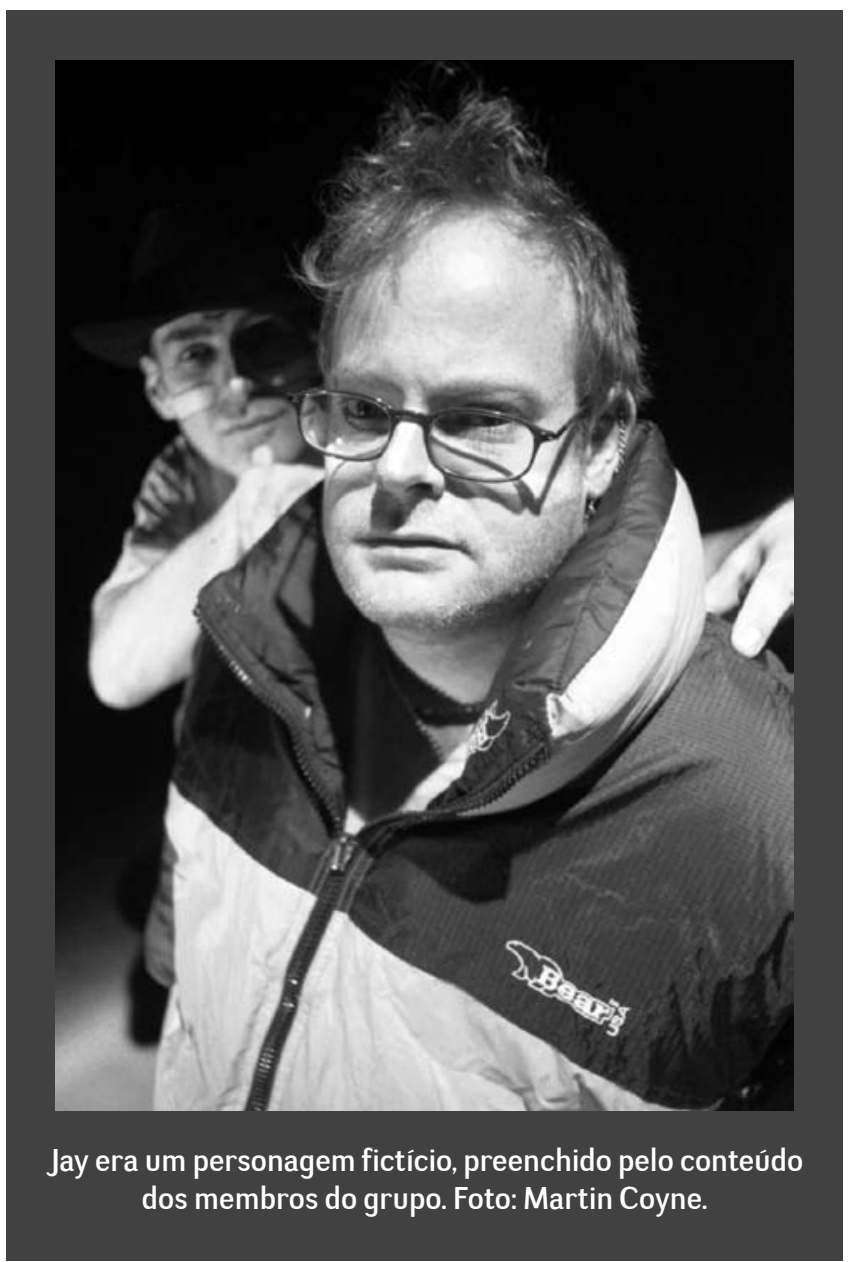


Sharon, em seguida, convidou o grupo para trabalhar com ela no Centro Cultural Comunitário de Bournemouth. Eles começaram a trabalhar uma vez por semana por algumas horas, e só aumentaram o número de reuniões e horas de trabalho depois de terem desenvolvido uma relação de confiança. Depois de três ou quatro semanas, eles se tornaram uma comunidade comprometida com a criação da peça.

Como parte do método Dialógico de Teatro para o Desenvolvimento, o facilitador (ou um grupo de facilitadores) chega em uma comunidade e começa a visitar locais diferentes da comunidade, conversando informalmente. Aqui Sharon visitou o espaço da comunidade, o Clubhousee,emseguida, noCentroCultural, começaram a trabalhar informalmente para dar espaço para que uma relação de confiança fosse desenvolvida.

Sharon começou a trabalhar com a linguagem teatral, incluindo o trabalho com improvisação, dinâmica de grupo, dramatização e criação de imagens. Eles não começaram a trabalhar sobre o tema das drogas antes de terem atingido um nível de amadurecimento na relação entre eles.

Participei de uma das actividades deste workshop inicial, oferecido por Sharon, durante a conferência de 2000 do National Drama, em York, como uma forma de apresentar seu trabalho com o Vita Nova. Sharon mostrou-nos uma fotografiaretirada do jornal The Guardian, que retratava uma situação de refugiados curdos. Tal como aconteceu com o grupo Vita Nova, os participantes foram convidados a "ler" a imagem, com atenção para os detalhes, e depois a assumir as posições das pessoas na foto. Todos devem estar envolvidos e, como havia mais participantes no workshop do que pessoas na foto, fomos convidados a criar novos personagens, como parte de uma mesma situação.

Era uma situação humana profunda, retratando pessoas excluídas. Não estava relacionada às drogas, mas Sharon disse que os membros do Vita Nova puderam se identificar facilmente com as emoções expressas pelos personagens da foto. Esta fase inicial gerou um ambiente de profundidade e respeito e, lentamente, as histórias individuais do Vita Nova, começaram a emergir.

O programa de recuperação a que o grupo foi submetido ajudou neste processo. O programa de doze passos dos Narcóticos Anônimos incentiva as pessoas a falarem sobre seus problemas e a se apoiarem uns aos outros. Existem alguns paralelos entre a tentativa de dar voz aos participantes, que faz parte de experiências em trabalhos na linha do Teatro para o Desenvolvimento, e o que Sharon relata em seu diário sobre as habilidades desenvolvidas durante $\mathrm{o}$ tratamento de recuperação:

\begin{abstract}
Estou começando a perceber que o tratamento de recuperação, as reuniões e a rede de auto-ajuda, têm dado às pessoas com quem estou trabalhando uma habilidade enorme de ouvir, incentivando e apoiando uns aos outros. Talvez todos devessem ter por algum tempo a oportunidade de aprender e trabalhar com essas habilidades. É uma ironia que estas oportunidades só apareçam quando as pessoas estão em crise. Há muita coisa aqui que grupos que não estão em recuperação poderiam aprender. Não há dúvida que isso ajuda a dissipar, no grupo, uma sensação de fracasso, o que faz com que as pessoas se sintam confiantes para mostrar seu trabalho. Por conta desta dinâmica estamos progredindo mais rapidamente (MUIRURI, 1999, p. 9).
\end{abstract}

Outra semelhança com o método dialógico que pude identificar foi a atitude de Sharon de respeito pelo conhecimento do grupo e habilidades culturais. Diferente, por exemplo, do contexto muitas vezes relatado da experiência africana do Teatro Dialógico para o Desenvolvimento ${ }^{6}$ a ideia de utilizar as danças tradicionais, visando a valorização da cultura dos participantes, no contexto do Vita Nova isto não fazia sentido. No entanto, do meu ponto de

6 Ver, entre outros: ABAH, 1997; KIDD, 1984; MDA, 1993. 
vista, Sharon alcançou o mesmo objetivo ao inserir no espetáculo as habilidades culturais dos participantes. Um bom exemplo dessa prática é a incorporação da língua mãe de Elin, no espetáculo. Sharon ouviu-a falar em galês ${ }^{7}$ no telefone com a mãe e pediu para incorporar esse conhecimento na peça:

Perguntei como ela se sentiria se experimentasse falar em galês numa cena da peça. O resultado foi que Elin usou sua língua materna na parte mais dolorosa de sua fala e isso deu uma pungência extra para a cena. Duvido que alguma criança das escolas de Bournemouth tenham ouvido o gales ser falado antes. O público não entendia tudo o que estava sendo dito, mas isso não importa já que a emoção crua da situação era claramente comunicada (MUIRURI, 1999, p. 18).

O Scratchin' the Surface, como muitos outros trabalhos de Teatro para o Desenvolvimento, foi baseado em problemas do grupo. A primeira atividade diretamente ligada ao tema das drogas foi a construção de imagens estáticas com base em três recortes de jornais contendo manchetes tais como: ... ... "Repressão ao Comércio de Drogas Mortais" ... "Ecstasy a Droga Mortal" e "Substâncias Letais na Cultura Jovem do Principal Bar do Sul". Mais tarde, Sharon pediu-lhes para integrar uma imagem na outra, como parte de uma idéia de movimento contínuo (ibid., p. 9). A imagem de um DJ em uma casa noturna saiu em um sub-grupo e Sharon imediatamente percebeu o poder deste personagem e as potencialidades da casa noturna como um espaço central em torno do qual a peça pudesse se desenvolver. Era um lugar familiar para os membros da Vita Nova e acessível para o público adolescente. O outro sub-grupo mostrou diversas imagens de morte.

70 galês é uma língua do país de Gales que, durante a exploração colonialista inglesa, foi proibido de ser falado, levando esta língua a um perigo de extinção. Houve um movimento de resgate desta língua, mas, mesmo assim ela é raramente usada no cotidiano das pessoas.
Esta foi uma sessão importante. Temaschave da peça surgiram claramente ... a cena do bar, a importância do DJ, o peso visível do consumo de drogas, a armadilha inescapável do vício, que oferece apenas uma vida para a morte. Nós desenvolvemos e trabalhamos em todas estas áreas e as trouxemos para a nossa peça final (Ibid. p. 11).

O processo foi guiado por questões importantes: "Qual a idade que tinham quando começaram a se envolver com drogas, e qual foi a motivação para seu uso? (Ibid, p. 10) Essa questão contribuiu para concentrar o processo criativo em relação ao seu público-alvo. Qual foi o momento em que você decidiu procurar ajuda para recuperação? (Ibid. p. 12).

Estas questões abriram histórias que eram difíceis até de ouvir. Para o grupo era fácil falar, por conta do processo de recuperação que estavam vivendo. Para Sharon, foi muito doloroso, ela sentia, às vezes, que precisava de algum apoio para si mesma:

O que o grupo compartilhou comigo foi angustiante, doído... assustador. Eles descrevem um mundo completamente virado de cabeça para baixo, desesperado e solitário:

Você encontra-se em um hospital sem ninguém para ajudá-lo. Amigos morrendo e isso não tem nenhum significado.

Nós vivemos uma existência louca em um quarto com cortinas pretas e usando óculos escuros.

Você em desespero quebra a sua própria moral.

Você não se importa com mais nada, além de uma nova dose.

As mortes não têm qualquer impacto sobre você. Você só pensa no que aconteceu com o carro dele.

Meu amigo morreu. Ele tinha 17 anos. Ele engasgou com seu próprio vômito, mas você acha que nunca vai acontecer contigo.

Você enfrenta a mortalidade. Sozinho ... desesperado.

Minha namorada cometeu suicídio.

Mundo do crime, tentativa de homicídio. 
Você está na beira do precipício.

David contou-nos como a sua namorada morreu. Elin, de como quase perdeu a vida e seus filhos. Conversas, sem fim, sobre os acidentes que aconteceram. A recuperação incentiva as pessoas a falar. Eu não estava preparada para a profundidade de tragédias em suas histórias. Senti-me triste e exausta. No entanto, a qualidade do que se seguiu foi definitivamente uma evolução em nossa discussão (MUIRURI, 2000, p. 25).

Com todo esse material eles começaram a definir o espetáculo: sobre o que seria a peça? Eles decidiram focar na história em um jovem garoto chamado Jay. O personagem fictício seria preenchido pelo conteúdo de diferentesindivíduos do grupo. Cenas de Jay com seu pai, de Jay com sua mãe e com sua namorada foram improvisadas.

\section{Criação de h is tórias i mediat a s - ênfase no detalhe - onde o pai dele vive? Como é a sua casa?-Descrição. Nós construímos p r i m e i r o uma imagem detalhada do pai, em seguida, do filho.}

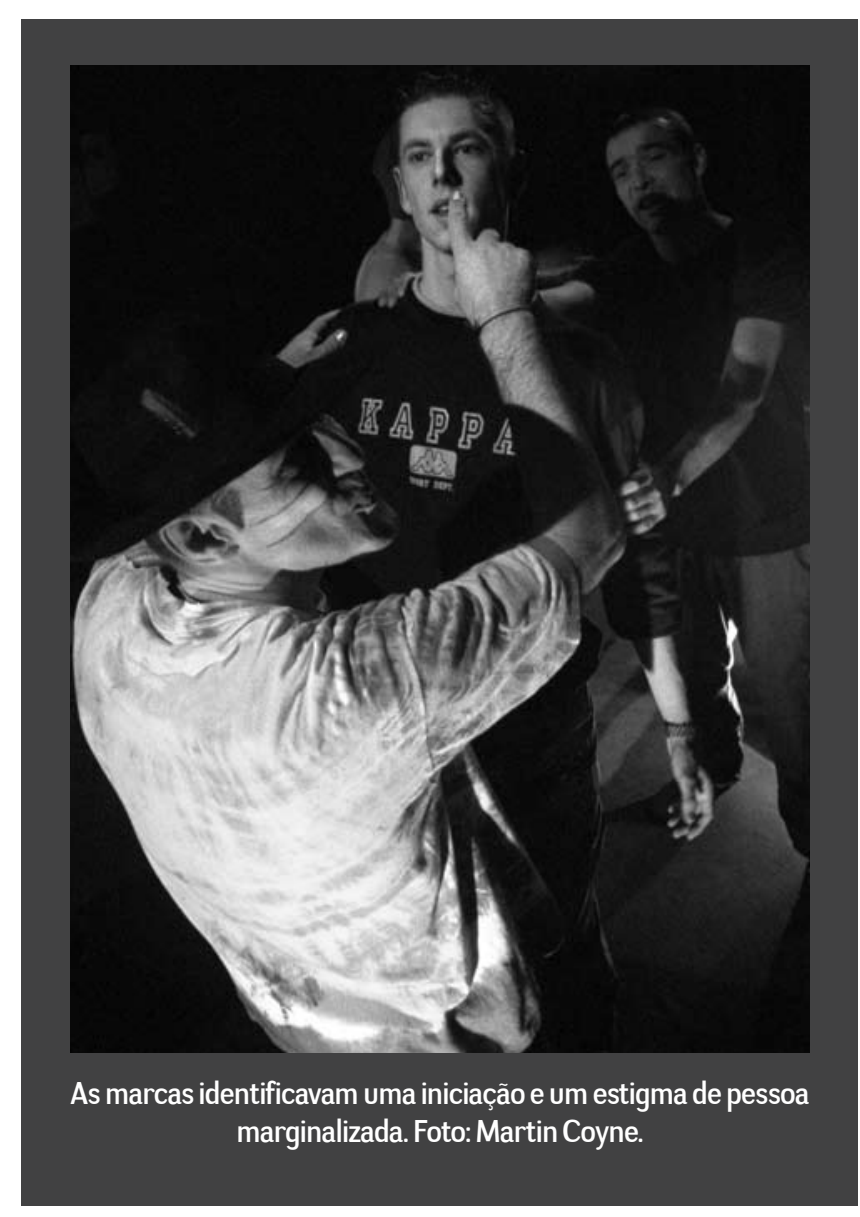
Decidimos

que a mãe tinha saído de casa para morar com um namorado mais jovem [...] Nós compartilhamos novamente cada cena. Começamos com Will e Geoff [atores do grupo], e repetimos a cena com algumas sugestões minhas e do resto do grupo. $\mathrm{Na}$ segunda vez ela já foi ganhando forma [...] Eu disse a Geoff e Will que, com apenas um pouco a mais de trabalho, esta cena iria fazer parte da nossa peça. Eles pareciam realmente impressionados você realmente quer dizer que vai entrar na peça? (MUIRURI, 1999, p. 13).
Nesse ponto Sharon trouxe uma contribuição importante. Ela conseguiu "traduzir" artisticamente o que tinha sido dito. Um extrato de seu diário nos ajuda a entender como ela propôs um personagem simbólico que deu uma nova dimensão para a peça:

Meia-noite de domingo, veio na minha cabeça que precisávamos deste personagem, alter ego, instigando Jay, sempre falando com ele. Eu tive uma visão de Tim [ator da peça] sentado em uma escada muito alta. Eu não podia esperar para contar-lhe.

" - Você sabe que todo mundo me diz que ele está sempre lá te desafiando, não vai deixar você esquecer!" " - Ah, você quer dizer o vício", ele respondeu. Há uma certa ironia no fato de que fui eu que pensei neste personagem e não outra pessoa! Estranho. Às vezes um estranho tipo de troca ocorria entre o grupo e eu. Era como se, de certa forma, eu havia me tornado uma espécie de canal ou até mesmo uma tradutora de suas histórias. Eu estava de fato devolvendo o que me foi dito, mas eu estava em algum sentido editando as histórias deles, dando forma ao que tinha me impactado, enquanto alguém que ouviu suas histórias pela primeira vez. Esse personagem de alter ego desenvolveuse num Corvo [Raven], representava o vício que simbolicamente elevava Jay para ele pudesse voar, mas no final Jay está arrastando Raven, sua carga, sua bagagem, seu vício (MUIRURI, 2000, p. 25-26).

Raven trouxe sentido e dinâmica para a peça. Quando Jay estava andando ele também estava carregando o peso 
de Raven sobre os ombros. Foi fácil reconhecer a imagem de um dependente, um usuário de drogas andando pesadamente. A solução cênica proposta por Sharon tornou o vício visível.

Raven promoveu os bons momentos de "voar", e mais tarde dominou toda a vida de sua vítima, influenciando Jay a se tornar mais e mais isolado, sempre pedindo mais um.

Outro elemento simbólico associado a Raven, na peça, é a dimensão tribal. Raven tem algumas marcas tribais em seu rosto e quando ele se aproxima de uma presa, ele faz algumas marcas tribais em seu rosto. Durante na peça, Jay tem seu rosto progressivamente pintado.

As marcas tribais são um símbolo aberto. Caracterizam uma subcultura, como a cultura dos jovens de fazer marcas no corpo, de coloração capilar, usando piercing, fazendo uma tatuagem, chegando, às vezes, num nível de auto-abuso, como se cortar e arranhar o corpo. Essas marcas são usadas por alguns jovens para se diferenciarem dos demais e da cultura dominante. Raven incorpora esta marcação tribal. Ela também poderia representar uma iniciação que leva ao uso de diferentes tipos de drogas, em uma dependência progressiva. Ela representa um estigma reconhecido pela sociedade, que identifica as pessoas marginalizadas.

Na última cena do jogo, Jay está em um hospital e Raven está deitado no seu travesseiro. Ainda pedindo mais um. No seu relatório, Sharon dá detalhes de como essa cena foi planejada:

Estamos posicionados Jay no chão com a cabeça no travesseiro que é dividido com Raven. Mãe e pai frente a frente e as palavras fluíram. Geoff de repente se levantou e foi até o piano e começou a tocar uma nota como um bip de hospital. Depois da mãe e do pai dizerem suas falas emocionais, Raven começou a incitar Jay. (Palavras de Will inspirado), estou começando a pensar que você é o problema ... Então Raven provoca Jay para ingerir apenas mais um ... Os dois saem de cena. Geoff faz seu bip virar numa linha contínua ... acho que quase todo mundo estava em lágrimas no final e nós soubemos então o que tinha acontecido - ele não era um esboço, mas uma cena virtual, perfeita (MUIRURI, 1999, p. 19).

Esta cena tornou-se um final aberto. Não estava explícito o que aconteceu com Jay: ele morreu? Seria ele um morto-vivo? Essa pergunta abriu o debate que acontecia normalmente após o espetáculo.

Esta era uma outra similaridade com o Teatro Dialógico para o Desenvolvimento: o espetáculo com final em aberto para encorajar debates e manifestações da plateia. Nos espetáculos nas escolas, além dos debates, havia outros recursos para um diálogo aberto e frutífero. Cada aluno tinha a oportunidade de escrever perguntas anônimas. Havia formulários de avaliação para estudantes e para profesores e uma entrevista com alguns alunos depois de um determinado tempo.

Há no relatório de Sharon vários depoimentos de como esses debates nas escolas foram democráticos e abertos. Os jovens se sentiam a vontade para falar. Vita Nova nunca dizia 'não' para os alunos. Eles simplesmente apresentavam suas experiências pessoais de onde o consumo de drogas pode levar. Eles contribuíam apenas para uma escolha mais informada. Durante os debates, eles buscavam desmistificar questões em torno das drogas. Eles eram muito honestos:

\begin{abstract}
Não era de todo ruim ou você não faria isso. Mas a fase alta não durava muito. Tornava-se tão chato ... toda a sua vida dominada por uma nova dose ... como ser um morto ambulante. Nós fomos os sortudos, para cada um de nós há pelo menos meia dúzia dos nossos amigos que não conseguiram chegar até aqui ( MUIRURI, 1999, p. 29).
\end{abstract}

Analisando o significado geral do projeto proposto por Sharon, a principal semelhança com o Método Dialógico de Teatro para o Desenvolvimento está na perspectiva freireana assumida: os membros do grupo Vita Nova foram abordados como sujeitos e não objetos dos problemas de drogas. Os que entraram 
no lado negro do vício, geralmente marginalizados pela sociedade, eram vistos como os que poderiam contribuir melhor para ensinar as crianças. Eles eram os que tinham mais conhecimento sobre as drogas, a sua "especialização" foi mais reconhecida pelos jovens que assistiram a peça do que as campanhas antidrogas propostas pelos policias:

Os membros do Vita Nova eram capazes de falar a partir da experiência própria. Eles podiam dizer como se sente, os bons momentos, e também os maus. Eles não eram limitados como a polícia, em virtude da sua posição (MUIRURI, 2000, p. 20).

Finalmente, a relação entre Sharon e Nova Vita durou mais do que uma única apresentação bem-sucedida. Outro paralelo com o Teatro para o Desenvolvimento, relacionado com a necessida de dar seguimento (follow up) ao processo, mesmo após o processo criativo, Sharon manteve um compromisso com o desenvolvimento pessoal do grupo e o processo de recuperação. Criaram um novo espetáculo, A Mula, sobre o tráfico de drogas, ampliando a percepção do problema das drogas para além do problema da dependência; e desenvolveram um novo projeto, Sonhos de uma Noite de Verão, integrando o grupo com a polícia da comunidade.

Por causa de sua capacidade de trabalhar de igual para igual, Sharon recebeu o título de "viciada honorária', pelo grupo Vita Nova como: "Eu nunca pensei que iria me sentir tão orgulhosa de ser apelidada de viciada honorárias, mas este é um estranho velho mundo" (MUIRURI, 1999, p. 29).

Tal como outros espectáculos de Teatro para oDesenvolvimento, a realidade da vida dos atores foi outro elemento importante do drama. O fato de que o público sabia que eles eram viciados em drogas trouxe respeito em relação ao que estavam fazendo. A atitude honesta e dolorosa de expor seus problemas para ajudar outros a ter uma escolha mais informada foi sem dúvida um elemento importante do jogo.
Nem mesmo o ator mais hábil seria capaz de fazer a mesma coisa, para atingir o mesmo "efeito", isto estava presente na performance do grupo e nas discussões após a apresentação.

Enquanto facilitadora, Sharon foi capaz de traduzir estéticamente as imagens dos horrores do vício, criando um espetáculo de qualidade artítica. Esta dimensão não está sempre presente nos projetos de Teatro para o Desenvolvimento, mas sem dúvida ela trouxe mais significado para o trabalho.

\section{Referências bibliográficas}

ABAH, S. O. Performing Life: Case Studies in the Practice of Theatre for Development. Zaria: Bright Printing Press, 1997.

FREIRE, P. Pedagogia do Oprimido. Rio de Janeiro: Paz e Terra, 1977.

KIDD, R.. From People's Theatre for Revolution to Popular Theatre for Reconstruction: Diary of a Zimbabwean Workshop. The Hafgue: CESO, 1984.

MDA, Z., When People play People: development communication through theatre. London: Zed Books, 1993.

MUIRURI, Sharon. Scratchin' the Surface with Vita Nova. Londres: Drama Magazine 8, No1, 24-30, inverno de 2000.

.' 'Scratchin' the Surface: Drug
Education Project Report' Bournemouth
Theatre in Education, outono de 1999.
. 'Scratchin' the Surface: Working
with Vita Nova: Report Part III' Bournemouth
Theatre in Education, verão de 2000.
NOGUEIRA, Marcia Pompeo. Towards a
Poetically Correct Theatre for Development: a
Dialogical Approach. Tese de Doutorado,
Departamento de Drama, Universidade de
Exeter, Inglaterra, 2002.

